\title{
ON THE TIME CONSTANTS OF TACHISTOSCOPES*
}

\author{
J. D. MOLLON AND P. G. POLDEN \\ Department of Experimental Psychology, University of Cambridge \\ Downing Street, Cambridge $C B 2{ }_{3} E B, U . K$.
}

\begin{abstract}
The time constants of commercially available, electronic tachistoscopes are shown to be much poorer than is widely assumed. When a band near the centre of the visible spectrum is isolated, the output of a typical tachistoscope lamp takes approximately $18 \mathrm{~ms}$ to reach $90 \%$ of its asymptotic value; the time to decay to $10 \%$ is also typically $18 \mathrm{~ms}$ and we demonstrate conditions under which the decaying trace remains visually effective against a dark field for more than $40 \mathrm{~ms}$ after the nominal offset of the lamps.

Many reports of tachistoscopic experiments published in the last two decades must be quantitatively in error; and we provide examples of experiments where qualitative conclusions may have been drawn invalidly.
\end{abstract}

\section{Introduction}

In the winter of $1898 \mathrm{~W}$. H. R. Rivers was making preparations for the Cambridge Anthropological Expedition to the Torres Straits and his colleague Captain E. T. Dixon undertook the construction of a tachistoscope. The late C. Grindley used to tell the story of the letter from Dixon announcing that the tachistoscope was finished. The letter still survives among Rivers' papers. Dixon describes his calibration of the tachistoscope, reports that the rise time is $60 \mathrm{~ms}$ and concludes: "it would not do for very accurate experiments, but will I think be suitable for savages". We have recently examined a range of modern tachistoscopes and find that 80 years have brought little improvement. When care is taken to measure only visible radiation, the time constants of tachistoscope lamps prove to be very much longer than is claimed by manufacturers or assumed by users.

Almost all modern tachistoscopes are fitted with fluorescent lamps. Such lamps consist of a glass tube containing argon and a small quantity of mercury, which vaporises during operation. The inner surface of the tube is coated with phosphorescent materials. Passage of current between electrodes placed at opposite ends of the tube leads to changes in the energy levels of electrons in the individual mercury ions and thus radiation is emitted at a number of wavelengths in the ultraviolet and visible range. The strongest emission is at $253 \mathrm{~nm}$. The ultra-violet energy is absorbed by the phosphors and re-emitted as visible light. $\dagger$

\footnotetext{
"Based on a talk to the Experimental Psychology Society, Sheffield, March, 1977.

$\dagger$ Introductory accounts of fluorescent lamps are to be found in publications by Funke and Oranje (1951), Illuminating Engineering Society (1967), Hewitt and Vause (1966) and General Electric Company (1973). A very comprehensive discussion is provided by Elenbass (I971).
} 
The commonest phosphor used in modern white lamps is calcium halophosphate in combination with particular impurities, called activators. The combination of halophosphate and antimony produces an emission that is maximal in the blue, while the combination of halophosphate and magnesium produces a maximal emission in the yellow-orange band. Magnesium tungstate, which has a peak emission at $480 \mathrm{~nm}$, is sometimes used as an alternative for the blue phosphor (Ouweltjes, 1971). It is the long-wavelength phosphors that have long time constants, whereas the short-wavelength phosphors are fast (Sperling, 1960). An additional factor is that in the blue a significant proportion of the visible light is attributable directly to the mercury line at $436 \mathrm{~nm}$, whereas most of the longwavelength light is accounted for by secondary emission from the phosphors. If the properties of the lamp are examined with an unshielded photocell, much of the response will be attributable to u.v. and blue radiation and the temporal waveform will appear relatively rectangular. This will be especially true if calibrations are made with the common types of vacuum photocell that are most sensitive at short wavelengths. However, if filters are used to isolate the part of the spectrum to which the photopic eye is most sensitive and which is used for detailed form vision, then the time constants of tachistoscope lamps are seen to be very poor indeed.

Sperling (1960) presented a trace for an early Gerbrands tachistoscope fitted with 4-in. lamps of the "Daylight" type. This trace has a fast rise but a slow, exponential decay. We have made measurements on a number of modern, research tachistoscopes manufactured by Electronic Developments, Scientific Prototypes and Iconix. Decay constants resemble those found by Sperling but in addition we find that the rise time of the yellow component of the light is described by a time constant similar to that describing the delay.

\section{Methods}

Measurements in the United Kingdom were made with a PIN-ro silicon photodiode (United Detector Technology) and amplifier (type Ior A), which in combination had been spectrally calibrated by the National Physical Laboratory.

The photodiode has a linear response throughout the range used in these measurements. The amplifier was always used on its low-sensitivity setting, since the high-sensitivity circuit introduces a long time constant. By measuring the response to mechanically interrupted light, we checked that the combination of the photodiode and amplifier did not itself introduce the long time constants that were measured; and the reader will note that relatively fast rise and fall times were recorded for the tachistoscope lamps when it was the blue component of the output that was isolated (Fig. I). The waveform of the lamp's response was either traced or photographed from the face of an oscilloscope.

The photodiode is maximally sensitive to infra-red radiation. The latter was excluded from measurements by placing a minimum of $4 \mathrm{~mm}$ of $\mathrm{HA}_{3}$ glass immediately in front of the photodiode; and u.v. radiation was attenuated with a Wratten $2 \mathrm{~A}$ gelatin filter. Ilford spectral filters were additionally used to isolate portions of the visible spectrum. The Ilford 626 filter used to isolate a band of yellow light has a peak transmission of $575 \mathrm{~nm}$ and a bandwidth at half height of $35 \mathrm{~nm}$; the Ilford 622 filter used to isolate a band of blue light has a peak transmission at $480 \mathrm{~nm}$ and a bandwidth of $60 \mathrm{~nm}$.

The different filters produced different signal levels. Oscilloscope traces were brought to similar heights by adjusting the sensitivity of the oscilloscope or the distance of the photodiode rather than by adjusting the intensity controls of the tachistoscopes. Direct checks were made that the waveform did not depend on signal level. 
Measurements of the Iconix 6r 37 tachistoscope were made in New York in the Department of Physiological Optics, SUNY College of Optometry, with the collaboration of Dr B. Gillam and Mr T. R. Flagg. A PIN-ro photodiode was used and spectral regions were isolated by means of broad-band gelatin filters (Edmund Scientific). The Scientific Prototypes auto tachistoscope was measured at the Institute of Psychiatry, London.

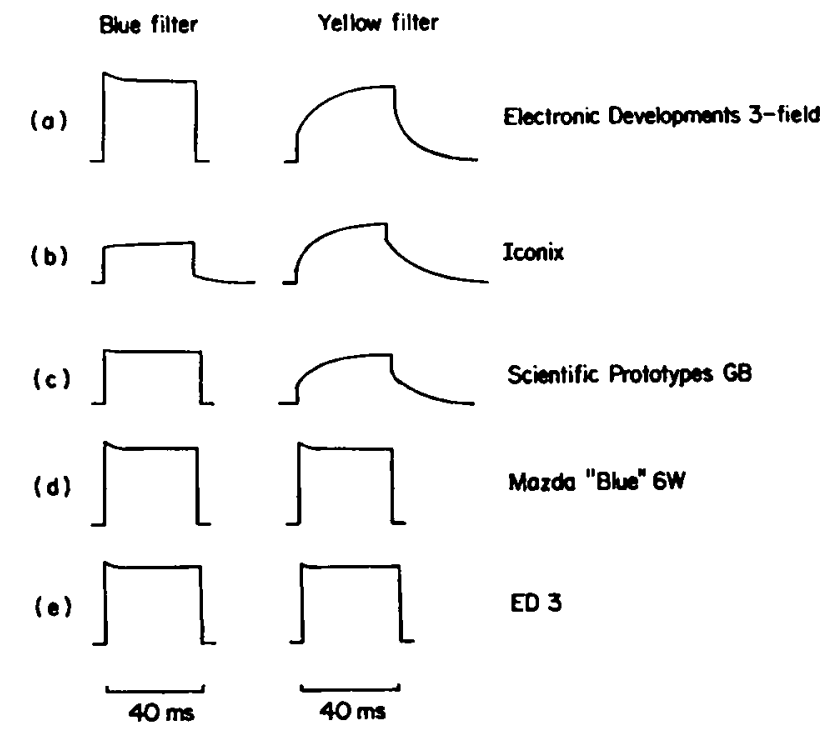

FIGURE 1. Outputs of tachistoscope lamps in response to (nominal) 40-ms logic pulses. Except in the case of (b), the "blue" filter was an Ilford 622 and the "yellow" was an Ilford 626. In case (b), broad-band Edmund Scientific filters were used. The Mazda "blue" lamp (d) was taken from the tachistoscope described by Kinsbourne and Warrington (r962a) and was marked "2096". The small initial overshoot seen in (d) and (e) could be eliminated by running the lamps at less than full intensity. A high-frequency modulation of about $10 \%$ at $5 \mathrm{kHz}$ was often noticed in the traces but this is probably not of visual significance and is not represented in the figure. Also not represented is residual mains ripple, which is probably a property of the lampdriver used rather than of the lamp.

\section{Results}

Figure I(a) shows results for an Electronic Developments 3-field tachistoscope, fitted with the lamps hitherto supplied, Sylvania F6T5D ("Daylight"). The nominal duration of the flash was always $40 \mathrm{~ms}$. When the short-wavelength part of the spectrum is isolated an almost rectangular trace is seen, with a slight overshoot during the first $5 \mathrm{~ms}$; but when a band near the centre of the visible spectrum is isolated, the lamp is seen to take $\sim 18 \mathrm{~ms}$ to reach $90 \%$ of its asymptotic value and more than $40 \mathrm{~ms}$ to reach its full output. The time for the output to fall to $\mathrm{I} / e$ is $5.5 \mathrm{~ms}$ but this is an inappropriate value to take, since at any given level of adaptation the eye has a dynamic range of several logarithmic units; moreover, early dark adaptation is very rapid: a gain in absolute sensitivity of $x \log _{10}$ unit would be expected in the first $40 \mathrm{~ms}$ following the offset of a brief stimulus of the luminance typically used in tachistoscopy (Crawford, 1947, Fig. 3). The F6T5D lamp takes $\sim 18 \mathrm{~ms}$ to fall to $10 \%$ of its peak output. Below we describe a demonstration in which the trace is visually effective against a dark field more than $40 \mathrm{~ms}$ after the nominal offset of the lamp. 
Similar measurements are provided in Figure $1(b)$ for the Iconix 6137 tachistoscope, which was found to be fitted with Sylvania F6T5/CW lamps. "Cool white" lamps of this type have a lower colour temperature than the "Daylight" type: a greater proportion of the total output is accounted for by long-wavelength phosphors. The time to fall to $\mathrm{I} / e$ is $6.5 \mathrm{~ms}$; the time to $10 \%$ is $\sim 24 \mathrm{~ms}$. That the time constants appear slightly poorer than even those of the "Daylight" lamps agrees with published data on fluorescent lamps (Illuminating Engineering Society, 1967).

The traces for the Scientific Prototypes GB tachistoscope are very similar to those for the Electronic Developments instrument. The markings of the Scientific Prototypes lamps have been over-painted but all that we have seen resemble the "Daylight" type. We have obtained similar records from Scientific Prototypes GB auto and N-1000 tachistoscopes.
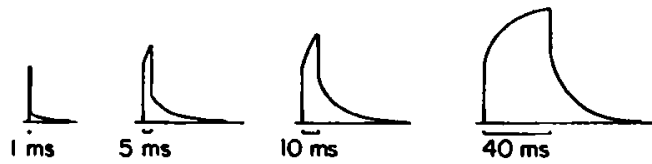

Electronic Developments
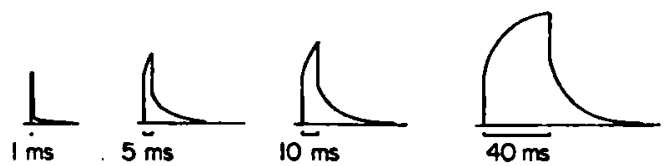

Scientific Prototypes GB

FigurB 2. Light outputs of Electronic Developments and Scientific Prototypes GB tachistoscopes at different values of the nominal duration of the flash. All measurements were made with an Ilford 626 filter.

Figure 2 shows how the yellow component of the output of typical tachistoscope lamps varies as a function of the nominal duration of the flash. It is clear that the very many experiments that have varied exposure duration in the range 0 to $50 \mathrm{~ms}$ have also unintentionally varied stimulus intensity."

\footnotetext{
-Early models of Scientific Prototypes GB tachistoscopes expose the unguarded experimenter to another danger when nominally short durations are in use. The programming unit is furnished with two contacts that may be shorted through an external key to initiate a stimulus cycle. Many experimenters have used this facility to allow subjects to trigger each presentation, an arrangement that probably does reduce the incidence of blinks and of lapses of attention or accommodation at the moment of presentation. However, few push-button switches or telegraph keys make a clean and instantaneous contact: the first 5 or $10 \mathrm{~ms}$ of contact are marked by mechanical chatter. The Scientific Prototypes timers respond to the first $25 \mu \mathrm{s}$ of a $-7 \mathrm{v}$ d.c. signal. Thus if a timer is set to a nominal duration of $\mathrm{I}$ or $2 \mathrm{~ms}$ it will be triggered several times as the circuit is repeatedly broken and re-established (Mollon, 1970, pp. 142-3). Where experimenters have allowed subjects to initiate very brief presentations and where no details of the switch are given, results must be suspect. Serious errors will have arisen where a brief target presentation was the first event in one experimental condition and a longer non-target stimulus was the first event in another condition: for example, in an experiment comparing forward and backward masking the target might be more energetic in the case of backward masking and thus the extent of masking may appear to be reduced. Errors of this kind are avoided in Electronic Developments tachistoscopes by routing the signals from the subject's push-button through a start-pulse generator that supplies noise-free signals to the timers.
} 
Since the output of the commonly-used "Daylight" lamp decays exponentially (Fig. I(a), (c)), it is difficult to specify the effective persistence. We have therefore prepared the following demonstration. Triads of random, upper-case letters, subtending 2 deg of visual angle in height, were mounted on white cards and exposed for $40 \mathrm{~ms}$ in an Electronic Developments 3-field tachistoscope. Illumination was provided by Sylvania F6T5D lamps and the intensity setting was maximum. An 8-mm circular aperture was mounted in front of the viewing hood and the vane of a fast electro-magnetic shutter (Bulova, ALC roo) was mounted between the aperture and the tachistoscope. The observer viewed monocularly through this aperture. During the nominal exposure of the card the shutter remained closed. $40 \mathrm{~ms}$ after the nominal offset of the lamps the shutter was opened and the observer attempted to report the letters on the card. The demonstration was conducted in low room illumination and no special steps were taken to dark-adapt the observer.

Six members of the Experimental Psychology Society were invited to inspect the demonstration and the apparatus. All were satisfied that, with only occasional errors, they could correctly report the letters on the card. As a control, we fitted $E_{3}$ lamps (see below and Fig. I(e)) to a second field of the tachistoscope and exposed target cards in this field, making no other change to the apparatus: no observer could report any letters.

Some early Electronic Development tachistoscopes were equipped with Mazda "Blue" lamps. Measurements of such a lamp are shown in Figure $I(d)$ and it can be seen that the temporal response is satisfactory. The initial overshoot is not seen if the lamp is run at less than full intensity. Studies performed with these lamps are not open to criticism; but the lamps had a bluish tinge and were probably little used before they went out of production some years ago.

One tachistoscope fitted with Mazda "Blue" lamps was that described by Kinsbourne and Warrington (1962a); and through the kindness of Dr Elizabeth Warrington we have been able to examine the actual lamps originally used. The near-rectangular traces shown in Figure $I(d)$ were in fact obtained from one of these lamps, driven, however, with an Electronic Developments lamp-driver. Another satisfactory tachistoscope was probably that described by Humphrey, Dawe and Mandell (1955), which was used for early experiments on backward masking: for the only phosphor used in its fluorescent lamps was magnesium tungstate, which has short time constants. Sperling (1965) identified a white lamp with satisfactory time constants, the Sylvania SDCW 14 W, and he used it in studies of masking by flashes. Unhappily this lamp did not remain in production.

\section{Discussion}

\section{Validity of measurements}

The claim that we are making is a strong one: it is that the commercial tachistoscopes in common use have almost never been properly calibrated by their users, despite the very large number of published studies that have used these instruments. Could it be that our own measurements are mistaken? For a number of reasons, we are satisfied that our results are sound. First, we have obtained similar records 
in different laboratories, using our own equipment and that of others. Second, we are able to measure short time constants when a blue filter is substituted for a yellow one or when an improved lamp is used (see Fig. I). Thirdly, our findings are compatible with published and unpublished measurements by lamp manufacturers (Illuminating Engineering Society, 1967). Slow phosphors are used in fluorescent lamps quite deliberately in order to reduce the flicker and the stroboscopic effects that are undesirable in everyday use.

The sceptical reader may readily himself examine the persistence of tachistoscope lamps by adopting the ancient device of transforming a temporal variation into a spatial one. This can be done in several ways. A repetitively flashing lamp can itself be moved about in a dark room; or its focussed image may be reflected from a rotating mirror; or a moving slit can be interposed between the viewer and a surface intermittently illuminated by the lamp; or the observer may make a saccadic eye movement across a stationary, flashing lamp. One convenient arrangement is to prepare a black disc on which is mounted a single thin white sector of approximately $10 \mathrm{deg}$ and to illuminate the disc with nominally brief (<10 ms) flashes while rotating it at $200 \mathrm{rev} / \mathrm{min}$ (it is helpful to tune the timing until the repetition rate of the flashes corresponds exactly to the rotation frequency of the disc). One sees a white bar preceded by a thin blue leading edge and followed by an extended orange sector; the angle subtended by the latter allows the duration of the after-glow to be estimated." When a tachistoscopic experiment is being prepared one may notice occasional yellow flashes, which occur when one makes an eye movement or moves an opaque object past an exposed flashing lamp. Many experimenters have probably seen these yellow flashes and dismissed them as subjective.

Some manufacturers of tachistoscopes have provided specifications for their instruments that are clearly incorrect by two or more orders of magnitude. Documents provided with the Iconix 6r37 mention "rise and fall times" of "less than $0.2 \mathrm{~ms}$ ". Scientific Prototypes, in handbooks for GB tachistoscopes, claim $5 \mu$ s as the rise and fall time, a figure that appears to be in error by $10^{4}$. Some manufacturers make much of devices that facilitate the initial striking of the lamps, such as preheating of the electrodes or the painting of a conductive strip along the length of the outside of the tube; but it should be emphasised that such refinements will affect only the primary $\mathrm{Hg}$ discharge and can in no way change the intrinsic time constants of the phosphors, which account for most of the visible output.

Siegel (1968) drew attention to the fact that the luminance of tachistoscope lamps varies with temperature but he made no criticism of the time constants; this is probably because he made his measurements with an unshielded, 934 vacuum phototube, which has a peak sensitivity of $400 \mathrm{~nm}$.

\section{Relevance of measurements}

Sakitt (1976) has suggested that iconic storage is a rod phenomenon. In the light of this claim, the present reader might suppose we have shown only that conventional tachistoscope lamps are very suitable for research in this field: the blue component of the output has the fast time constant and it is this radiation to which the rods are particularly sensitive.

*An arrangement of this kind was used to demonstrate the persistence of Sylvania F6T5/D lamps to the Experimental Psychology Society, March, 1977. 
It would be inappropriate to discuss Sakitt's experiments in detail here, but two brief comments may be adequate:

(I) The crucial Experiments 3 and 4 of Sakitt's paper show only that the wellknown rod after-image (Bidwell's Ghost; Purkinjesche Nachbild) is a rod afterimage. Using dark-adapted observers, dark pre- and post-fields, and a 500-ms or I000-ms criterion, she showed that coloured lights that produce an after-image of constant duration are lights that produce equal rates of isomerisation in the rods. This result complements the primitive action-spectrum given by Bidwell (1894) for the vividness of the image. Sakitt has not shown that phenomenal persistence depends on the rods under light-adapted conditions. Nor has she shown that in the case of normal observers the store defined by part-report procedures is ever located in the rods: even under dark-adapted conditions, the observer may well be able to base his phenomenal report on a blurred achromatic rod after-image while independently basing his part report on a concurrent visual memory of a crisp, green array of letters.

(2) The experiments discussed in detail below, which reflect a large field of tachistoscopic research, have little to do with scotopic processes that last $500 \mathrm{~ms}$. They are concerned with rapid sequences of stimuli during the first $50 \mathrm{~ms}$; photopic pre- and post-fields are sometimes present; the stimuli are in part or wholly foveal; and discrimination of high-frequency spatial information is often required. All these factors favour cone vision.

The chromatic aberration of the eye provides a further reason why it is the output at $575 \mathrm{~nm}$ rather than at $480 \mathrm{~nm}$ that is the more relevant to tachistoscopic experiments. At viewing distances typically used in tachistoscopy, the eye will be focussed for yellow or orange light; radiation at $480 \mathrm{~nm}$ will be out of focus by approximately I.O diopter (Millodot and Sivak, 1973).

\section{Implications}

It seems clear that quantitative errors must be present in a very large number of published studies that have used commercial tachistoscopes to present stimuli of brief duration. These include studies of backward masking, apparent movement, phenomenal duration, visual latencies, order judgements and information processing. The stimulus parameters given and the results plotted or tabulated will be in error. Nevertheless, in most cases, the experiment will not be invalidated, since many studies in this field are concerned only to test a qualitative prediction and the only important result is a significant effect of a given sign.

We believe that experiments genuinely invalidated by the time constants of tachistoscope lamps are relatively rare; but we cite some examples as illustrative warnings.

\section{Backevard masking}

Our first two examples are taken from a paper by Turvey (1973). This paper has enjoyed high regard, since it is one of the few papers in the field that test quantitative predictions. We emphasise that our present criticisms are confined to the individual experiments that we take as examples. 
(1) In Experiment II of his paper Turvey asked "whether it is target exposure per se or the quantity of light in the stimulus that is important" in determining the critical inter-stimulus interval (ISI) at which a mask ceases to affect performance. He used a Scientific Prototypes GB tachistoscope. (Nominal) target durations were in the range $2-8 \mathrm{~ms}$ and (nominal) intensity was adjusted to ensure that the total energy in the stimulus remained constant (two of the intended targets are depicted in Fig. 3 (a)). The masks were random noise patterns. Under these conditions,

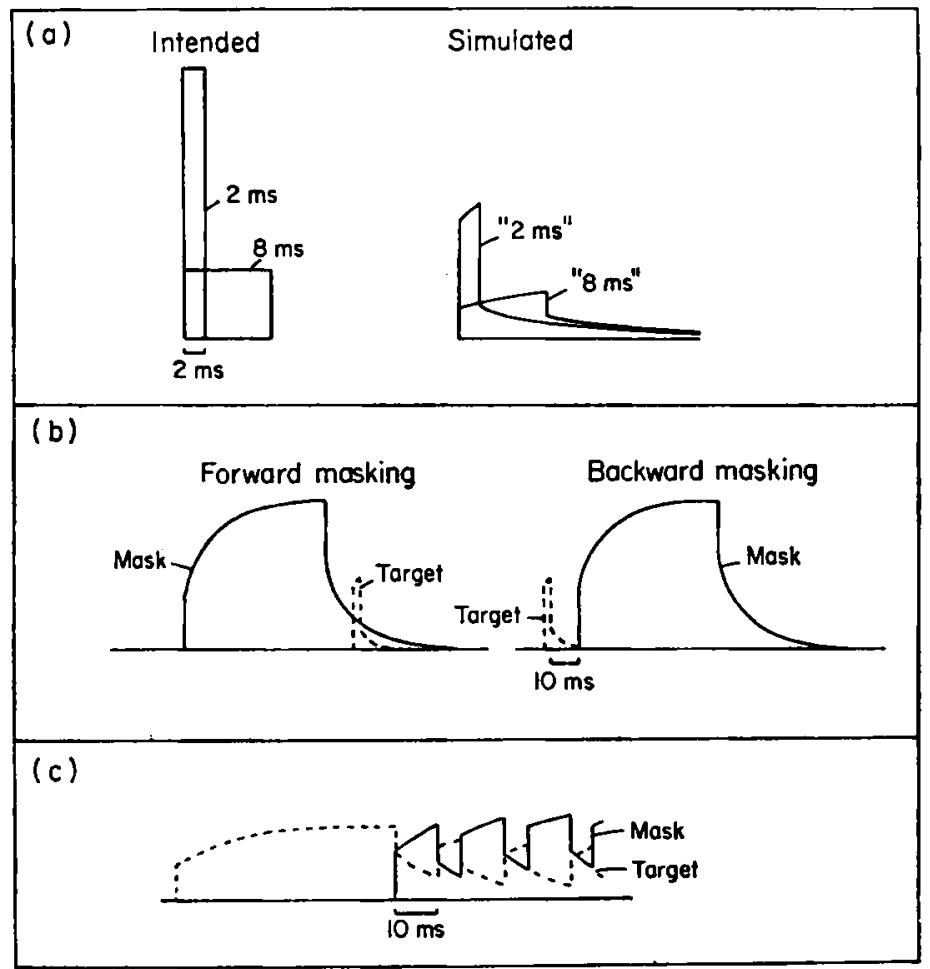

Figurs 3. (a) Reconstruction of stimuli used by Turvey (1973, Experiment 2). The left-hand diagram represents the intended intensities and durations of two of his stimuli. The right-hand diagram represents (on the same scale) the probable waveforms of the yellow component of the stimuli and is reconstructed from actual traces from Scientific Prototypes lamps. (b) Forward and backward masking in a tachistoscope. The figure is constructed from actual traces for 2-ms and 50-ms flashes and shows how a significant physical superimposition may occur in forward masking. A nominal ISI of $10 \mathrm{~ms}$ has been assumed. The traces were obtained from an Electronic Developments tachistoscope using an Ilford 626 filter and holding the nominal intensity at a constant value. (c) Reconstruction of the yellow component of the stimuli used by Erwin (1976) in his experimental condition. The dashed line represents the temporal variation in the intensity of the target and the solid line represents that of the mask.

masking appeared to be governed by Bloch's Law: the maximum ISI at which a target was retroactively masked by the random pattern remained constant as duration and intensity were reciprocally varied. But the reconstructions of Figure 3(a) (right-hand traces) show that Turvey's stimuli would not in fact be the temporally rectangular pulses intended but would be integrated in the phosphors of the lamps 
before they were actually delivered to the retina. Their durations and intensities would not differ by the factors intended. To prepare the simulation of Figure 3(a) we used actual traces from lamps supplied by Scientific Prototypes and driven by a GB lamp-driver. An Ilford 626 filter was used in addition to filters blocking IR and UV radiation. Our measurements show that more than half the $575-\mathrm{nm}$ energy in the "2-ms" target would be emitted after the nominal offset of the flash. Who is to say whether these stimuli differ significantly in their effective duration?

(2) Turvey (1973, Experiments XIV, XV, XVI) also reported that forward masking of a brief target by a longer-lasting random pattern is greater than backward masking. Figure $3(\mathrm{~b})$ shows how this result may be open to a simple physical explanation. The reconstructions of this figure are prepared from actual traces from "Daylight" lamps. We have taken a mask duration (nominally $50 \mathrm{~ms}$ ) and a target duration (nominally $2 \mathrm{~ms}$ ) that are typical for Turvey's Experiment XV. The nominal intensities of target and mask were identical. Figure $3(\mathrm{~b})$ shows that at relative short ISI's the long after-glow of the phosphor will lead to actual superimposition of mask and target in the case of "forward" masking, whereas no significant superimposition occurs in the backward case. At somewhat greater ISI's an effective superimposition will be produced by the temporal integration that Turvey himself takes as the physiological basis of masking under these conditions; and whatever the extent and weighting function we assume for the period of integration, within a large range, it will always be true that at a given nominal ISI more of the energy of the mask will be integrated with the target in the case of forward masking than in the case of backward masking.

The reader may object that Kinsbourne and Warrington $(1962 b)$ reported a similar asymmetry of forward and backward masking under (partially) similar conditions."We have ourselves shown that Kinsbourne and Warrington's lamps were satisfactory (Fig. I(d)). Therefore (it might be argued) Turvey's experiments can be accepted. But this will not do. Turvey's experiments cannot take their support from Kinsbourne and Warrington's finding and at the same time serve as replications and extensions of the earlier result.

(3) "Visual Persistence". An experiment by Erwin (1976) was intended to test the hypothesis that visual persistence is "an active continuously operating process rather than a passive neural copy of the stimulus". In all conditions a foveal array of seven letters was presented for (nominally) $50 \mathrm{~ms}$ at a luminance that varied across subjects but averaged $17 \mathrm{~cd} / \mathrm{m}^{2}$. In control conditions this stimulus was followed either by a blank field or by a $500-\mathrm{ms}$ continuous mask of $27 \mathrm{~cd} / \mathrm{m}^{2}$. In the experimental condition the initial $50-\mathrm{ms}$ exposure of the target was followed by a further train of 5 -ms presentations of the target separated by $10-\mathrm{ms}$ presentations of the $27-\mathrm{cd} / \mathrm{m}^{2}$ mask. The intention was to make the target physically available for a total duration that was equivalent to the visual persistence in the control condition with the blank field; since the extent of this visual persistence could not be exactly known, the trains of alternating mask and target were of several different lengths (in the range $130-410 \mathrm{~ms}$ ). Erwin argued that if visual persistence were

*An important difference is that in Kinsbourne and Warrington's experiment the background field, which was present in the interval between mask and target, was of similar luminance to the patterned stimuli, whereas in Turvey's experiments it was $2.88 \log _{10}$ units dimmer than the target and mask, i.e. the background was effectively dark. 
merely a "neural echo" then performance should be similar whether the information was extracted from a persisting representation or from the physically extended stimulus. An Electronic Developments 3-field tachistoscope was used.

The number of letters reported in the experimental condition was in fact only half the number reported when a blank field followed the initial exposure, although performance was still poorer when a continuous 500-ms mask followed the initial array. An odd aspect of the results was that performance in the experimental condition was independent of the length of the train, a finding for which Erwin offers no explanation.

In Figure $3(c)$ we have used actual traces from an Electronic Developments tachistoscope to simulate the first $100 \mathrm{~ms}$ of Erwin's experimental condition. There is clearly no mystery why performance is poorer in this condition than it is when a blank field follows the initial presentation: the mask is physically superimposed on the target. Our reconstruction also suggests why performance is independent of the length of the train in the range 130-410 ms: conditions for discrimination are most favourable at the beginning of the train. By the third cycle the intensity of the target has so declined and the intensity of the mask has so increased that the two are of similar value during the 5 -ms intervals in which the target is supposed to be present alone.

(4) Differences between $\pi$ mechanisms. An important study that may be marred by the use of fluorescent lamps (not in this case fitted to a tachistoscope) is that of Green (1969), who measured the temporal modulation-transfer-function for isolated colour mechanisms (the $\pi$ mechanisms of W. S. Stiles). Brindley, Du Croz and Rushton (1966) had shown that the critical flicker-fusion-frequency for the bluesensitive mechanism has a maximal value of only $18 \mathrm{~Hz}$, a value about three times less than that for the red- and green-sensitive mechanisms; but Green argued that this result arose from a difference in contrast sensitivity rather than in time constants: the blue mechanism was less sensitive at all frequencies but the high frequency portion of its MTF had a shape similar to those of the long-wavelength mechanisms. Other evidence, however, does suggest a true difference in time constants (Mollon and Krauskopf, 1973). Green used a Mazda Daylight fluorescent tube and reported that the frequency response of the output was flat from 0 to $500 \mathrm{~Hz}$; but his calibrations were made with a vacuum photocell (RCA type 934) that has maximum sensitivity at $\sim 400 \mathrm{~nm}$ and is very insensitive to long wavelengths. The modulation of his long-wavelength stimuli was probably attenuated at high frequency and thus a difference in time constants between the blue mechanism and the long-wavelength mechanisms may have been concealed.

(5) Equation of coloured targets for rod vision. An instructive example is provided by a recent test of Sakitt's hypothesis (see above) that iconic storage is a rod phenomenon. The principle of this test (Banks and Barber, 1977, Experiments I and 2) was to present stimuli that differed in colour but were of the same scotopic brightness (i.e. were indistinguishable to the rods). Part report was required at varying delays. In one condition the stimuli were coloured rectangles; in another they were coloured letters on a field of a different colour but the same scotopic brightness. Stimuli were prepared from sheets of coloured paper and were presented for $50 \mathrm{~ms}$ in an Iconix tachistoscope fitted with "Cool White" lamps. 
Aware that the papers would be matched only under given conditions of illumination, the authors took great care to check that their stimuli were scotopically matched when they were illuminated dimly by light from the tachistoscope lamps.

Unhappily, although the stimuli were scotopically matched under steady illumination they would not remain matched during a brief flash. Consideration of Figure I(b) shows that the colour temperature of the illumination would fall markedly in the course of the flash: the light would first be bluish, would then briefly match the steady illumination, and would finally be orange. The letter targets would be presented to the rods in first one contrast and then in the other. The rods are not simple structures and no one could safely say what after-effect such a sequence of stimulation would leave. This crucial test of Sakitt's hypothesis remains to be performed properly.

(6) Interaction with retinal position. The considerable variation of spectral sensitivity across the retina may interact with temporal variation in the spectral output of the lamps.

Merikle, Coltheart and Lowe (1971), using a Scientific Prototypes GB tachistoscope, reported that backward pattern masking was greatest for the central items in a horizontal row of eight letters subtending in total $3.5 \mathrm{deg}$; and the phenomenon was confirmed by Henderson and Park (1973), who used an Iconix 6I37 tachistoscope. The difference between central and eccentric positions is found only when several letters are present. Further studies (see Butler, 1975) have been taken to suggest the following generalisation: provided the subject is required to identify all the targets, processing of a horizontal array begins with the outermost letters; if the subject can take a short-cut (because there is an undelayed part-report cue or because he must identify only the category of the items) then the selective masking effect does not occur. (Note, however, that Henderson and Park were unable to abolish the effect with selective pay-offs).

The selective masking effect has been taken as evidence that, in the absence of other constraints, detailed analysis begins at the ends of an array (see, e.g. Merikle, Coltheart and Lowe, 1971). For this hypothesis to be of interest it would have to refer to a general characteristic of the human operator. But there is perhaps a particular and technical explanation of why analysis begins at the ends of the array in the experiments cited. It is well established that the fovea is less sensitive than is the parafovea to short-wavelength targets, owing largely to the presence of macular pigment and, less importantly, to a paucity of blue-sensitive receptors (see Wyszecki and Stiles, 1967; Bornstein, 1975; Sperling, 1977; Mollon and Polden, 1977, Experiment 6): the maximum optical density of the macular pigment may be as high as $0^{\circ} 42$ at $480 \mathrm{~nm}$, a wavelength close to the peak output of the blue phosphors used in fluorescent lamps (Wyszecki and Stiles, 1967 , Table 2.8.). It is the short-wavelength output from tachistoscope lamps that has the short time constants. Thus in the experiment of Merikle et al. the effective stimulus may actually be physically present earlier in the parafovea; and thus (ceteris paribus) the peripheral targets may be processed first simply because they are first to reach their contrast threshold. It is true that the effective ISI will be similar for foveal and parafoveal targets, since in the fovea the effective mask will be delayed as well as the target. What needs to be eliminated is the possibility that the first stimuli to be physically 
present are able to deflect attention and so pre-empt the analysers; for this to occur the parafoveal targets may require a temporal advantage that is quite small in relation to the time required to identify a single letter.

We have no idea whether variations in spectral sensitivity do account for the entirety of the selective masking effect, but these variations must contaminate the published results and the phenomenon deserves investigation with adequate apparatus. Our primary purpose in citing this example is to illustrate the danger of using conventional tachistoscopes when retinal position is an experimental variable.

\section{Remedies}

We are not suggesting that the electronic tachistoscope should be universally abandoned. There is no need for concern where a tachistoscope is being used simply to ensure a controlled exposure of $100 \mathrm{~ms}$ or more; or where nominal "duration thresholds" are being compared and no quantitative prediction is being tested.

Where, however, exposures are brief and duration and intensity are critical, conventional tachistoscope lamps should be eschewed. Alternative means of modulating light are discussed by Boynton (1966). Liquid crystals may sometimes offer a convenient solution but at present introduce difficulties of their own (Mollon, Polden and Morgan, 1977). The happiest solution would be a better tachistoscope lamp. The difficulties revealed by the present investigations have led to the preparation of an improved white lamp, type $E D_{3}$, which is now available from Electronic Developments Ltd." These lamps are designed to be fitted to the 3-field tachistoscope manufactured by Electronic Developments. $\dagger$ Figure I(e) shows a record of the response of an $\mathrm{ED}_{3}$ lamp to a 40-ms pulse: rise times and fall times are less than $100 \mu \mathrm{s}$. The maximum intensity of the new lamps is approximately $67 \%$ of that of the F6T 5 D lamps that they replace. Any residual ripple on the power supply to the lamps will be more visible when $\mathrm{ED}_{3}$ lamps are in use: this, of course, is no fault of the lamps but a necessary consequence of their improved time constants.

We are grateful to O. J. Braddick, C. R. Cavonius, P. MacLeod, A. Marcel, S. Monsell and G. Sperling for discussion and advice; and to J. Colbourne, T. R. Flagg and L. Spillmann for collaboration in measuring tachistoscopes. We especially wish to thank $\mathrm{Mr}$ W. C. R. Withers of Electronic Developments Ltd., who has very readily supplied us with information throughout this investigation. The measurements were supported by grants from the Medical Research Council and the Wellcome Trust.

\section{References}

Banks, W. P. and Barber, G. (1977). Color information in iconic memory. Psychological Review, 84, 536-46.

BrDwzLl, S. (1894). On the recurrent images following visual impressions. Proceedings of the Royal Society, 56, 132-45.

*37/E Platt's Eyot, Lower Sunbury Road, Hampton, Middlesex TWr2 2 HF, United Kingdom. Tachistoscopes currently supplied are fitted with $\mathrm{ED}_{3}$ lamps.

†The optical system for this instrument is described by Mollon (1970). 
BoRNsteIN, M. H. (1975). Spectral sensitivity of the modulation-sensitive mechanism of vision: effects of field size and retinal locus. Vision Research, 15, 865-9.

Boynton, R. M. (1966). In Sidowski, J. B. (Ed.), Experimental Methods and Instrumentation in Psychology. Pp. 319-21. New York: McGraw Hill.

Brindley, G. S., Du Croz, J. J. and Rushton, W. A. H. (1966). The flicker fusion frequency of the blue sensitive mechanism of colour vision. Fournal of Physiology, 183, 497-500.

BuTLRR, B. (1975). Selective attention and target search with brief visual displays. Quarterly Fournal of Experimental Psychology, 27, 467-77.

Crawford, B. H. (1947). Visual adaptation in relation to brief conditioning stimuli. Proceedings of the Royal Society, Series $B, 134,283-302$.

Er.rnBass, W. (1971) (Ed.). Fluorescent Lamps: Philips Technical Library. MacMillan: London.

ERwin, D. E. (1976). The extraction of information from visual persistence. American Fournal of Psychology, 89, 659-67.

Funkr, J. and Oranje, P. J. (r951). Gas Discharge Lamps. Philips Technical Library, N.V. Phillips' Gloeilampenfabrieken: Einhoven.

Grarar Electric Company (1973). Fluorescent Lamps. G.E. Publication No. TP-III: Cleveland, Ohio.

GRERN, D. G. (1969). Sinusoidal flicker characteristics of the color-sensitive mechanisms of the eye. Vision Research, 9, 591-601.

HENDERson, L. and PARK, N. (1973). Are the ends of tachistoscopic arrays processed first? Canadian Fournal of Psychology, 27, 178-83.

HewrrT, H. and Vause, A. S. (Eds) (1966). Lamps and Lighting. Arnold: London.

Humphrey, G., Dawr, P. G. M. and Mandell, B. (1955). New high-speed electronic tachistoscope. Nature, $176,231$.

Illuminating ENGINEERING SOCIETY (1967). Lighting Handbook. Illuminating Engineering Society: New York.

KnNsBourns, M. and Warkington, Elizabeth K. (1962a). The effect of an after-coming random pattern on the perception of brief visual stimuli. Quarterly Yournal of Experimental Psychology, 14, 223-34.

KinsBourne, M. and Warrington, Elizabeth K. (1962b). Further studies on the masking of brief visual stimuli by a random pattern. Quarterly fournal of Experimental Psychology, 14, 235-45.

Marc, R. E. and Sperling, H. G. (1977). Chromatic organisation of primate cones. Science, 196, 454-6.

Merikie, P. M., Coltheart, M. and Lowe, D. G. (1971). On the selective effects of a patterned masking stimulus. Canadian fournal of Psychology, 25, 167-74.

Millodot, M. and Sivak, J. (1973). Influence of accommodation on the chromatic aberration of the eye. British Yournal of Physiological Optics, 28, r69-74.

Mollon, J. D. (1970). Temporal factors in perception. D.Phil. Thesis. University of Oxford.

Mollon, J. D. and Krauskopf, J. (1973). Reaction time as a measure of the temporal response properties of individual colour mechanisms. Vision Research, 13, 27-40.

Molzon, J. D. and Polden, P. G. (1977). An anomaly in the response of the eye to light of short wavelengths. Philosophical Transactions of the Royal Society, Series B, 278, No. 960 .

Mollon, J. D., Polden, P. G. and Morgan, M. J. (1977). Electro-optic shutters and filters. Quarterly Yournal of Experimental Psychology, 29, 147-56.

OuwELTJES, J. L. (1971). Luminescence, fluorescence and phosphorescence. In ELENBass, W. (Ed.), Fluorescent Lamps. Philips Technical Library, MacMillan: London.

SAkITT, B. (1976). Iconic memory. Psychological Review, 83, 257-76.

SIEGEL, M. H. (1968). A note on luminance control in tachistoscopes. Behavioural Research Methods and Instrumentation, I, 33. 
SPERLING, G. (1960). The information available in brief visual presentations. Psychological Monographs, 74, Whole No. 798.

SperLING, G. (1965). Temporal and spatial visual masking. I. Masking by impulse flashes. Fournal of the Optical Society of America, 55, 541-59.

TURVEY, M. T. (1973). On peripheral and central processes in vision: Inferences from an information-processing analysis of masking with patterned stimuli. Psychological Review, 80, 1-52.

Wyszecki, G. W. and Stiles, W. S. (1967). Colour Science, Concepts and Methods. Quantitative data and formulas. New York: Wiley.

Revised manuscript received 21 February 1978 